\title{
Analysis of contextual-related variables on serve and receiving performances in elite men's and women's table tennis players
}

\author{
Miguel-Ángel Gómez ${ }^{\mathrm{a}}$ (D), Antonio García-de-Alcaráz ${ }^{\mathrm{a}, \mathrm{b}}$ (D) and Philip Furleyc
}

aFaculty of Physical Activity and Sport Sciences-INEF, Universidad Politécnica de Madrid, Madrid, Spain; ${ }^{\text {bLFE }}$ Research Group, Faculty of Physical Activity and Sport Sciences-INEF, Universidad Politécnica de Madrid, Madrid, Spain; 'Institute of Training and Computer Science in Sport, German Sport University Cologne, Köln, Germany

\begin{abstract}
The goal of the study was to identify the serve and reception effectiveness in relation to selected contextual-related variables in elite table tennis players. The sample comprised 140 matches from the men's and women's 2016 Olympic Games Tournament $(N=70$, respectively). The contextual-related variables considered were: quality of opposition; the dominant hand of the players; match and set duration; biggest lead; most consecutive points in each set; deficit overcome; and previous set outcome. Bivariate correlations, independent samples comparisons, and multiple linear regressions were applied to identify the influence of contextual variables on performances when serving and receiving during the match/set. The analyses demonstrated that serving in table tennis does not necessarily provide a big advantage with points won when serving being only slightly higher than $50 \%$. Performance when receiving was slightly below $50 \%$ and varied substantially as a consequence of contextual variables (e.g. biggest lead, most consecutive points, quality of opposition, great deficit overcome, and match duration) in men's and women's matches. The results highlight the importance of contextual variables on serve and reception performance in table tennis during the match. Implications in regard to coaching strategies and training programmes are discussed.
\end{abstract}

\section{ARTICLE HISTORY}

Received 6 November 2017

Accepted 16 November 2017

\section{KEYWORDS}

Racket sport; notational analysis; effectiveness; contextual variables

\section{Introduction}

Performance analysis in sport aims to understand players' or teams' behaviour with the goal of enhancing competitive performance and training processes. Recording relevant data is a prerequisite for this. With the rapidly advancing technological development the field of performance analyses in sport is flourishing (O’Donoghue, 2010). Therefore it is not surprising that performance analysis has been widely implemented in a majority of sports, including major racket sports (badminton, squash, tennis, and table tennis). However, within racket sports the sport of table tennis has received the least research attention (Lees, 2002). The limited available research that does exist in the field of table tennis has only provided 
information in a descriptive and comparative way (Loh \& Krasilshchikov, 2015; Malagoli Lanzoni, Di Michele, \& Merni, 2014; Zhang, Liu, Hu, \& Liu, 2013), or in a probabilistic way (Pfeiffer, Zhang, \& Hohmann, 2010). This research has focused on technical-tactical evaluations (Malagoli Lanzoni et al., 2014; Pfeiffer et al., 2010; Zhang et al., 2013) and the structural demands of the game (Leite, Barbieri, Miyagi, Malta, \& Zagatto, 2017; Loh $\&$ Krasilshchikov, 2015). To the best of our knowledge, no predictive studies have been conducted to investigate into the influence of contextual factors on serve and reception effectiveness during table tennis matches. However, the contribution of contextual variables can be considered a crucial factor in explaining the emergence of behaviours and game patterns based on the interaction between players and the information that arises from the environment (Vilar, Araújo, Davids, \& Button, 2012).

The behaviour of table tennis players has been proposed to emerge in a dynamical, interactive and non-lineal manner during the game (Glazier, 2010). Ecological approaches have described these behaviours in terms of a self-organised response to the contextual constraints of the situation (McGarry, Anderson, Wallace, Hughes, \& Franks, 2002; Palut \& Zanone, 2005). Net-racket sports are characterised by alternating possession. Players interact in dyadic confrontations (i.e. one vs. one; or two vs. two in doubles) (McGarry et al., 2002) that occur an indefinite number of times during a rally. This interaction in table tennis has been described as a non-linear dynamical system (Glazier, 2010). Each rally starts with a serve, thus, the serve represents the starting point of the dynamic interaction between the two opponents and may perturb the system and create an advantage for the server during the confrontation. In a recent press release, Bialik (2016) showed the average advantage for teams/players when serving in Olympic net sports. Serving had the biggest advantage for the server in tennis (more than 60\%). Whereas, it was more of a disadvantage in beach volleyball (less than $40 \%$ ). In table tennis, the possession of the serve only brought a slight advantage to the server (53\%).

The serve in table tennis is the first strike and plays an important role from a tactical perspective (Malagoli Lanzoni et al., 2014) due to a broad range of options concerning spin, placement, rhythm and speed (Zhang et al., 2013). Thus, the serve can be considered one of the most important shots in table tennis as it is under full control of the server and not influenced by previous behaviour of the opponent. In this respect the serve can potentially create an initial advantage to the server, in spite of the constraints posed by the official table tennis rules (bouncing the ball first in the server's court try to minimise the advantage of server) (Tamaki, Yoshida, \& Yamada, 2017).

Previous research (Malagoli Lanzoni et al., 2014) has shown that the server's advantage (i.e. the probability of winning a rally) is higher in relatively short rallies up to the third shot, while the probability of winning a rally for the receiver increases after the fourth-sixth shot. Hence, the advantage of the serve is lost as the duration of the rally increases, specifically after the third shot. Although this pattern slightly differs between genders, the tendency is very similar (Tamaki et al., 2017). These data confirm the "three phase evaluation theory", which is highly influential amongst Chinese table tennis coaches and players (Zhang et al., 2013). This theory emphasises the relationship between the serve and the first three shots of a rally. Further, it argues that the initial serve affects the rally dynamic by influencing the interactive behaviours between players. Of relevance for the present research, the opponent can be described as an important constraint affecting performance in racket sports 
(McGarry \& Franks, 1996) that can influence serving behaviour and subsequent interaction in table tennis.

Further, the analysis of contextual-related factors could be useful for training and competition performance in order to obtain objective information on the dynamic influence of situational factors on the serve in table tennis. This kind of analysis has led to important insights in other net sports, in which the serve has been related to the quality of opposition, game period, and game duration (Marcelino, Sampaio, \& Mesquita, 2012). Therefore, the aim of the present study is to identify the serve and reception effectiveness in relation to selected contextual-related variables (i.e. quality of opposition, the previous game outcome, and the score) during the full matches and each set. This will not only expand knowledge in the field of performance analysis in sport, but will also have practical applications in table tennis.

In addition, the fact that the player has to play best of seven sets (i.e. has to win 4 sets) to win the match may emerge different trends during the sets and in turn influence players' serve and reception abilities according to the context (e.g. due to changes in pressure, previous positive/negative behaviours). Moreover, the challenge of playing a close match (against similarly ranked players) during a knockout competition (Sève, Ria, Poizat, Saury, \& Durand, 2007) might further impact on serve and reception performance. Thus, it seems reasonable to hypothesise that serve and reception performances can be affected by contextual-related variables in elite table tennis players (and potentially differently depending on gender and the current sets).

\section{Methods}

\subsection{Sample}

The sample comprised 140 matches from the men's and women's 2016 Olympic Games Tournament ( $N=70$, respectively), played by 70 players in each gender category. The descriptive information (continent, country, number of players, number of games played, playing style, ranking, and dominant hand) for men's and women's players are presented in Tables 1 and 2. Over 75\% of players played one or two matches (77.14\% in men and $75.71 \%$ in women's category) while the remaining players played three to six matches. Also, the majority of players was right-handed ( $80 \%$ men and $78.6 \%$ women) and performed with an offensive style (except for seven players, 3 men and 4 women). The style of play was defined by McAfee (2009) with defensive players using specific rubbers (long pimples-out) on the backhand to chop, slice or block the strokes, while offensive players have regular rubbers (pimples in) to play more aggressively using top-spin. The players' description was done according to this approach and the International Table Tennis Federation classification of players (http://ittf.com/2016/08/09/defensive-art-solutions-found/). The data was collected from the official open access web domain of Rio 2016 (https://www.olympic.org/table-tennis) and the International Table Tennis Federation (http://www.ittf.com/rankings/). The local institutional review board approved this study. 
Table 1. Sample features information for male table tennis players.

\begin{tabular}{|c|c|c|c|c|c|c|}
\hline Continent & Country & Players & Games & Style & Ranking & Hand \\
\hline \multirow[t]{3}{*}{ Africa } & Congo & 2 & 4 & OFF & >Top 100/>Top 100 & $\mathrm{R} / \mathrm{L}$ \\
\hline & Egypt & 2 & 3 & OFF & >Top 100/>Top 100 & $\mathrm{R} / \mathrm{R}$ \\
\hline & Nigeria & 2 & 6 & OFF & Top 50/>Top 100 & $\mathrm{R} / \mathrm{R}$ \\
\hline \multirow[t]{7}{*}{ America } & Brazil & 2 & 5 & OFF & Top 50/>Top 100 & $\mathrm{R} / \mathrm{L}$ \\
\hline & Canada & 1 & 3 & OFF & Top 100 & $\mathrm{R}$ \\
\hline & Cuba & 2 & 2 & OFF & >Top 100/>Top 100 & $\mathrm{R} / \mathrm{L}$ \\
\hline & Mexico & 1 & 2 & OFF & $>$ Top 100 & $\mathrm{R}$ \\
\hline & Paraguay & 1 & 2 & OFF & $>$ Top 100 & L \\
\hline & Puerto Rico & 1 & 2 & OFF & $>$ Top 100 & $\mathrm{R}$ \\
\hline & USA & 2 & 2 & OFF & >Top 100/>Top 100 & $R / R$ \\
\hline \multirow[t]{12}{*}{ Asia } & China & 2 & 10 & OFF & Top 10/Top 10 & $\mathrm{R} / \mathrm{R}$ \\
\hline & Chinese Taipei & 2 & 3 & OFF & Top 10/Top 50 & $\mathrm{R} / \mathrm{L}$ \\
\hline & Hong Kong & 2 & 3 & OFF & Top 10/Top 20 & $\mathrm{R} / \mathrm{R}$ \\
\hline & India & 2 & 2 & OFF & $>$ Top 100/> Top 100 & $\mathrm{R} / \mathrm{R}$ \\
\hline & Islam. Rep. Iran & 2 & 3 & OFF & $>$ Top 100/>Top 100 & $\mathrm{R} / \mathrm{R}$ \\
\hline & Japan & 2 & 9 & OFF & Top 10/Top 20 & $\mathrm{~L} / \mathrm{L}$ \\
\hline & Kazakhstan & 1 & 1 & OFF & $>$ Top 100 & $\mathrm{R}$ \\
\hline & Qatar & 1 & 2 & OFF & Top 50 & $\mathrm{R}$ \\
\hline & Rep. Korea & 2 & 3 & OFF & Top 10/Top 20 & $\mathrm{R} / \mathrm{R}$ \\
\hline & Singapur & 2 & 2 & OFF & Top 50/>Top 100 & $\mathrm{R} / \mathrm{R}$ \\
\hline & Thailand & 1 & 2 & OFF & $>$ Top 100 & $\mathrm{~L}$ \\
\hline & Uzbekistan & 1 & 2 & OFF & $>$ Top 100 & $\mathrm{~L}$ \\
\hline \multirow[t]{22}{*}{ Europe } & Austria & 2 & 2 & OFF & Top 50/Top 50 & $\mathrm{R} / \mathrm{R}$ \\
\hline & Belarus & 1 & 5 & OFF & Top 10 & $\mathrm{R}$ \\
\hline & Croatia & 1 & 1 & OFF & Top 20 & $\mathrm{R}$ \\
\hline & Czech Republic & 2 & 2 & OFF & Top 100/Top 100 & $\mathrm{R} / \mathrm{R}$ \\
\hline & Denmark & 1 & 2 & OFF & Top 50 & $\mathrm{~L}$ \\
\hline & Finland & 1 & 2 & OFF & Top 100 & $\mathrm{R}$ \\
\hline & France & 2 & 2 & OFF & Top 20/Top 50 & $\mathrm{R} / \mathrm{L}$ \\
\hline & Germany & 2 & 5 & OFF & Top 10/Top 20 & $\mathrm{R} / \mathrm{L}$ \\
\hline & Greece & 1 & 2 & DEF & Top 50 & $\mathrm{R}$ \\
\hline & Hungary & 1 & 2 & DEF & Top 100 & $\mathrm{R}$ \\
\hline & Poland & 2 & 3 & OFF & Top 50/Top 100 & $\mathrm{R} / \mathrm{R}$ \\
\hline & Portugal & 2 & 4 & OFF & Top 20/Top 20 & $\mathrm{R} / \mathrm{L}$ \\
\hline & Roumania & 2 & 7 & OFF & Top 100/Top 100 & $\mathrm{R} / \mathrm{R}$ \\
\hline & Russia & 1 & 2 & OFF & Top 50 & $\mathrm{R}$ \\
\hline & Serbia & 1 & 2 & OFF & Top 100 & L \\
\hline & Slovakia & 1 & 2 & DEF & Top 100 & $\mathrm{R}$ \\
\hline & Slovenia & 1 & 4 & OFF & Top 100 & $\mathrm{R}$ \\
\hline & Spain & 1 & 2 & OFF & Top 100 & $\mathrm{~L}$ \\
\hline & Sweden & 2 & 3 & OFF & Top 50/Top 50 & $\mathrm{~L} / \mathrm{L}$ \\
\hline & Turkey & 1 & 1 & OFF & Top 50 & $\mathrm{~L}$ \\
\hline & Ukraine & 1 & 3 & OFF & Top 50 & $\mathrm{R}$ \\
\hline & United Kingdom & 2 & 6 & OFF & Top 50/Top 100 & $\mathrm{R} / \mathrm{R}$ \\
\hline \multirow[t]{2}{*}{ Oceania } & Australia & 2 & 2 & OFF & >Top 100/>Top 100 & $\mathrm{R} / \mathrm{R}$ \\
\hline & Vanuatu & 1 & 1 & OFF & $>$ Top 100 & $\mathrm{R}$ \\
\hline
\end{tabular}

Notes: $\mathrm{OFF}=$ offensive; $\mathrm{DEF}=$ defensive; $\mathrm{R}=$ right-handed; $\mathrm{L}=$ left-handed.

\subsection{Procedures}

Professional technicians from Rio 2016 gathered the data. However, in order to assess the data validity a sub-sample of four matches ( 2 for each sex) were randomly selected and observed by two experienced analysts (with more than 10 years of experience in performance analysis in sports). The results showed a high reliability (coefficients of agreement of 1.0 for points won and lost by each player in each set of the match, and $>0.96$ for sets and match duration).

The variable serve and reception effectiveness was defined as a percentage (\%) of the total points won and lost when serving and receiving, respectively. Due to the fact that in 
Table 2. Sample features information for female table tennis players.

\begin{tabular}{|c|c|c|c|c|c|c|}
\hline Continent & Country & Players & Games & Style & Ranking & Hand \\
\hline \multirow[t]{4}{*}{ Africa } & Congo & 1 & 2 & OFF & $>$ Top 100 & $\mathrm{R}$ \\
\hline & Egypt & 2 & 3 & OFF & >Top 100/Top 100 & $\mathrm{R} / \mathrm{L}$ \\
\hline & Nigeria & 2 & 4 & OFF & $>$ Top 100/>Top 100 & $R / R$ \\
\hline & Tunissia & 1 & 1 & OFF & $>$ Top 100 & $\mathrm{R}$ \\
\hline \multirow{7}{*}{ America } & Brazil & 2 & 4 & OFF & $>$ Top 100/>Top 100 & $R / R$ \\
\hline & Canada & 1 & 2 & OFF & $>$ Top 100 & $\mathrm{R}$ \\
\hline & Colombia & 1 & 1 & OFF & $>$ Top 100 & $\mathrm{R}$ \\
\hline & Mexico & 1 & 2 & OFF & $>$ Top 100 & $\mathrm{R}$ \\
\hline & Puerto Rico & 1 & 2 & OFF & Top 100 & $\mathrm{R}$ \\
\hline & USA & 2 & 5 & OFF & Top 100/>Top 100 & $R / R$ \\
\hline & Venezuela & 1 & 1 & OFF & $>$ Top 100 & $\mathrm{R}$ \\
\hline \multirow[t]{13}{*}{ Asia } & China & 2 & 10 & OFF & Top 10/Top 10 & $\mathrm{R} / \mathrm{L}$ \\
\hline & Chinese Taipei & 2 & 6 & OFF & Тор 20/Top 50 & $R / R$ \\
\hline & DPR Korea & 2 & 9 & DEF & Top 50/Top 100 & $R / R$ \\
\hline & Hong Kong & 2 & 4 & OFF & Top 50/Тop 50 & $R / R$ \\
\hline & India & 2 & 2 & OFF & $>$ Top $100 />$ Top 100 & $R / R$ \\
\hline & Islam. Rep. Iran & 1 & 1 & OFF & $>$ Top 100 & L \\
\hline & Japan & 2 & 6 & OFF & Top 10/Top 10 & $\mathrm{R} / \mathrm{L}$ \\
\hline & Lebanon & 1 & 1 & OFF & $>$ Top 100 & $\mathrm{R}$ \\
\hline & Philippines & 1 & 1 & OFF & $>$ Top 100 & L \\
\hline & Rep. Korea & 2 & 4 & DEF/OFF & Top 20/Top 20 & $\mathrm{R} / \mathrm{L}$ \\
\hline & Singapur & 2 & 6 & OFF & Top 10/Top 20 & $R / R$ \\
\hline & Syria & 1 & 1 & OFF & $>$ Top 100 & $\mathrm{R}$ \\
\hline & Thailand & 2 & 5 & OFF & Top 100/Top 100 & $R / R$ \\
\hline \multirow[t]{17}{*}{ Europe } & Austria & 2 & 3 & OFF & Top 100/Top 100 & $\mathrm{~L} / \mathrm{L}$ \\
\hline & Belarus & 2 & 5 & DEF/OFF & Top 100/Top 100 & $R / R$ \\
\hline & Czech Republic & 2 & 3 & OFF & Top 100/Top 100 & $R / R$ \\
\hline & France & 1 & 3 & OFF & Top 100 & $\mathrm{R}$ \\
\hline & Germany & 2 & 4 & OFF & Top 10/Top 20 & $\mathrm{R} / \mathrm{L}$ \\
\hline & Hungary & 2 & 4 & OFF & Top 50/Top 100 & $R / R$ \\
\hline & Luxembourg & 1 & 3 & OFF & Top 100 & $\mathrm{~L}$ \\
\hline & Netherlands & 2 & 3 & OFF & Top 50/Top 50 & $\mathrm{R} / \mathrm{L}$ \\
\hline & Poland & 2 & 3 & OFF & Тор 100/Top 100 & $R / R$ \\
\hline & Portugal & 2 & 2 & OFF & Top 50/Top 100 & $R / L$ \\
\hline & Roumania & 2 & 5 & OFF & Top 50/Top 100 & $R / L$ \\
\hline & Russia & 2 & 2 & OFF & Top 100/Top 100 & $R / R$ \\
\hline & Slovakia & 2 & 3 & OFF & Top 100/Top 100 & $R / L$ \\
\hline & Spain & 2 & 2 & OFF & Тор 100/Тop 100 & $\mathrm{R} / \mathrm{L}$ \\
\hline & Sweden & 2 & 4 & OFF & Top 50/Top 100 & $R / L$ \\
\hline & Turkey & 1 & 1 & OFF & Top 50 & $\mathrm{R}$ \\
\hline & Ukraine & 1 & 2 & OFF & Top 100 & $\mathrm{R}$ \\
\hline \multirow[t]{2}{*}{ Oceania } & Australia & 2 & 4 & OFF & >Top 100/>Top 100 & $\mathrm{R} / \mathrm{L}$ \\
\hline & Fiji & 1 & 1 & OFF & $>\operatorname{Top} 100$ & $\mathrm{R}$ \\
\hline
\end{tabular}

Notes: $\mathrm{OFF}=$ offensive; $\mathrm{DEF}=$ defensive; $\mathrm{R}=$ right-handed; $\mathrm{L}=$ left-handed.

table tennis each play starts with a serve ( 2 serves alternating between each player, and 1 serve when the score reaches 10-10) and the opponent returning, the efficiency of one of them is 100 minus the efficiency of the other because each point is scored by one of them. Although, we are aware that serve and reception are related to one another, we decided to treat them as independent in the present research as the aim of this study was to analyse the serve and reception performances separately according to contextual-related variables since these variables might have different effects on serve and reception. According to Zhang et al. (2013) the serve and reception actions (first strokes of each point) are key variables to understanding players' performance. The serve is the first stroke that is not restricted (related) to his/her opponents and potentially sets up favourable conditions for the next stroke; and the reception depends on the serve and determines whether the player is going to be on the offensive or the defensive. As contextual-related variables are likely to 
have differential effects on serve and reception performance respectively, we analysed their influence individually in the present research.

The contextual-related variables considered were: (a) quality of opposition (the difference between ranking positions of the two confronting players was used according to the international table tennis ranking gathered prior to the Olympic Games; $\mathrm{QO}=$ Ranking player A - Ranking player B); (b) the dominant hand of the players (the laterality of the player as right or left holder). This variable was coded for server and receiver in each condition separately; (c) match and set durations were gathered in minutes similarly to available research (Leite et al., 2017; Ming, Keong, \& Ghosh, 2008); (d) biggest lead (indicated the highest difference of points that a players reached during a set); (e) most consecutive points in a row in each set (the largest number of points won in a row without points won by the opponent); (f) deficit overcome (the largest number of points that a player got trying to comeback when trailing); and (g) previous set outcome (the differences of performance when the player won or lost the previous set).

\subsection{Statistical analysis}

The data analysis of serving and reception actions were analysed separately, assuming that each action in table tennis is differently affected by contextual-related variables configuring unique confrontations during each match/condition (Malagoli Lanzoni et al., 2014; Zhang et al., 2013). According to this approach all the statistical analyses were done separately for serve and reception effectiveness.

Firstly, exploratory analyses of the data were performed to identify the assumptions of normality (Kolmogorov-Smirnov test using the Lilliefors correction) (Ntoumanis, 2001). This revealed normal distribution for the following variables: serve and reception effectiveness, match duration, biggest lead, most consecutive points, and great deficit overcome. For sets variables that differed from normality non-parametric statistics were applied. Following the exploratory analysis, bivariate correlations (Pearson's correlation for match performances and Spearman's correlation for sets performances) were computed to identify the relationships between serve/reception effectiveness and contextual variables. Subsequently independent samples test ( $t$-test and Mann Whitney- $U$ test for match and sets performances, respectively) was applied to differentiate the dominant hand of the player (right or left handed) and the previous set outcome (differences between win and lose the previous set).

Secondly, in order to estimate the effect of independent variables on the player's serve and reception effectiveness a linear regression model was applied. The model was performed considering the final match performances (data normally distributed). The models did not showed heteroscedasticity in residuals or multicollinearity amongst regressors (using the Durbin-Watson test). In addition, the RESET test of Ramsey (1969) did not show specification problems. Positive or negative coefficients indicate a positive (greater) or negative (lower) propensity to increase or decrease the player's effectiveness when serving or receiving. The multiple linear regression models for match performances (1) were as follows:

Serve/Reception effectiveness

$$
\begin{aligned}
= & \beta_{0}+\beta_{1} \times \text { Quality of opposition }+\beta_{2} \times \text { Hand } \\
& +\beta_{3} \times \text { Biggest lead }+\beta_{4} \times \text { Most consecutive points } \\
& +\beta_{5} \times \text { Great deficit overcome }+\varepsilon_{i}
\end{aligned}
$$


where: $\beta_{0}$ is the intercept of the regression model; $\beta_{\mathrm{x}}$ are the effects of the regressors; and $\varepsilon_{i}$ is the disturbance term. Statistical analyses were performed using SPSS 22.0 (IBM Corp., Armonk, NY, USA). The level of significance was set at $p \leq 0.05$.

\section{Results}

The descriptive results for serve and reception effectiveness are presented in Table 3 . The results showed values greater (but closer) to $50-55 \%$ when serving and lower than $50 \%$ when receiving ( $43-50 \%)$ for male and female players. The greater difference between serve and reception performances occurred in women's matches, in the majority of the sets. Additionally, the results of bivariate correlation analyses between quality of opposition and serve and reception effectiveness are included in Table 3. The results showed significant correlations for serve effectiveness in both genders during sets $1-5$, and with reception effectiveness during sets 1-6 amongst male players and during sets 1-5 amongst female players.

Correlations between serve/reception effectiveness and match/set duration, biggest lead, most consecutive points, and greatest deficit overcome are presented in Table 4. The results showed no significant correlations with match/set duration for any analysis. There were significant correlations in both genders for (i) biggest lead in all the analyses for serve and reception (match and sets); (ii) most consecutive points for serve and reception for both genders with the exception of serve during the set 7 in men's players and reception during set 7 in women's players; and (iii) greatest deficit overcome in all the analyses for men's players.

The results for the differences between right and left-handed players are presented in Table 5. No significant differences were found amongst both genders for serve and reception performances between left and right holder players. The effect of the previous set outcome is also presented in Table 5. The results were only significant for serve and reception effectiveness during the set 2, 3 and 4 (better values after winning the previous set of the match: 1st, 2nd and 3rd) in female players.

The results of the multiple linear regression analysis for match serve and reception effectiveness in men and women's players are presented in the Table 6 . The results of the model for serve effectiveness showed significant positive effects for biggest lead (with increments of 2.32 and 2.42 for male and female players, respectively) and most consecutive points for female players (increments of 1.77 points), but negative effects (decrements) for quality of opposition ( -0.02 points for both men's and women's players) and match duration in men's matches (decrements of 0.14 points). For the reception effectiveness, the results showed negative effects for quality of opposition on men's and women's players ( -0.02 points) and positive effects for biggest lead in male and female players (increments of 1.99 and 1.59 points, respectively), for most consecutive points in female players (2.30 points) and deficit overcome in male players (1.32 points). The player's dominant hand was neither significant for serve nor for reception effectiveness in both genders.

\section{Discussion}

The aim of this study was to analyse the serve and reception performances according to contextual-related variables in elite male and female table tennis players. According to Yu, Zhang, and $\mathrm{Hu}$ (2008) elite table tennis performance is determined by technical, tactical, physical, psychological, and contextual-related factors. Obviously technical and tactical 


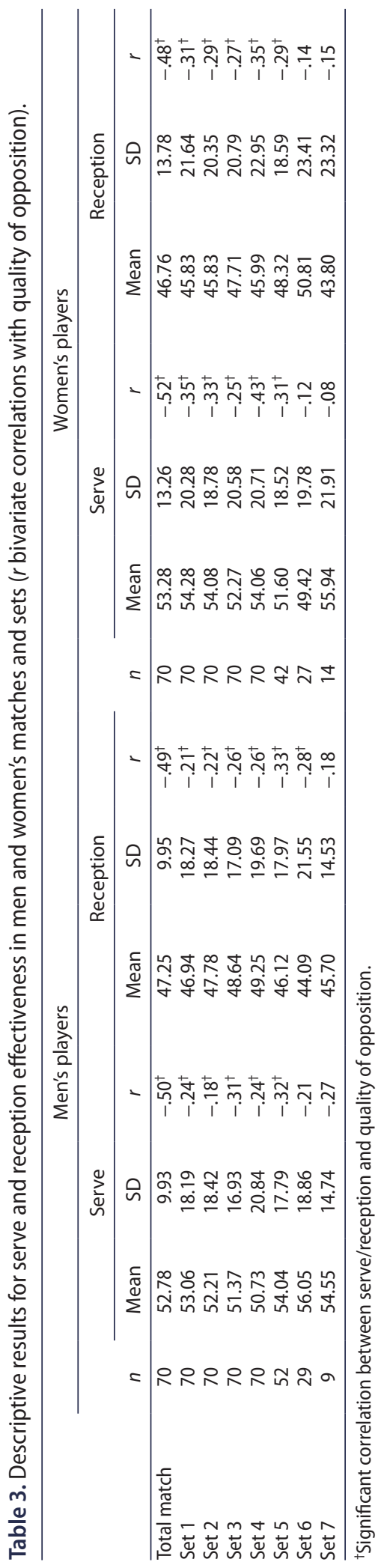




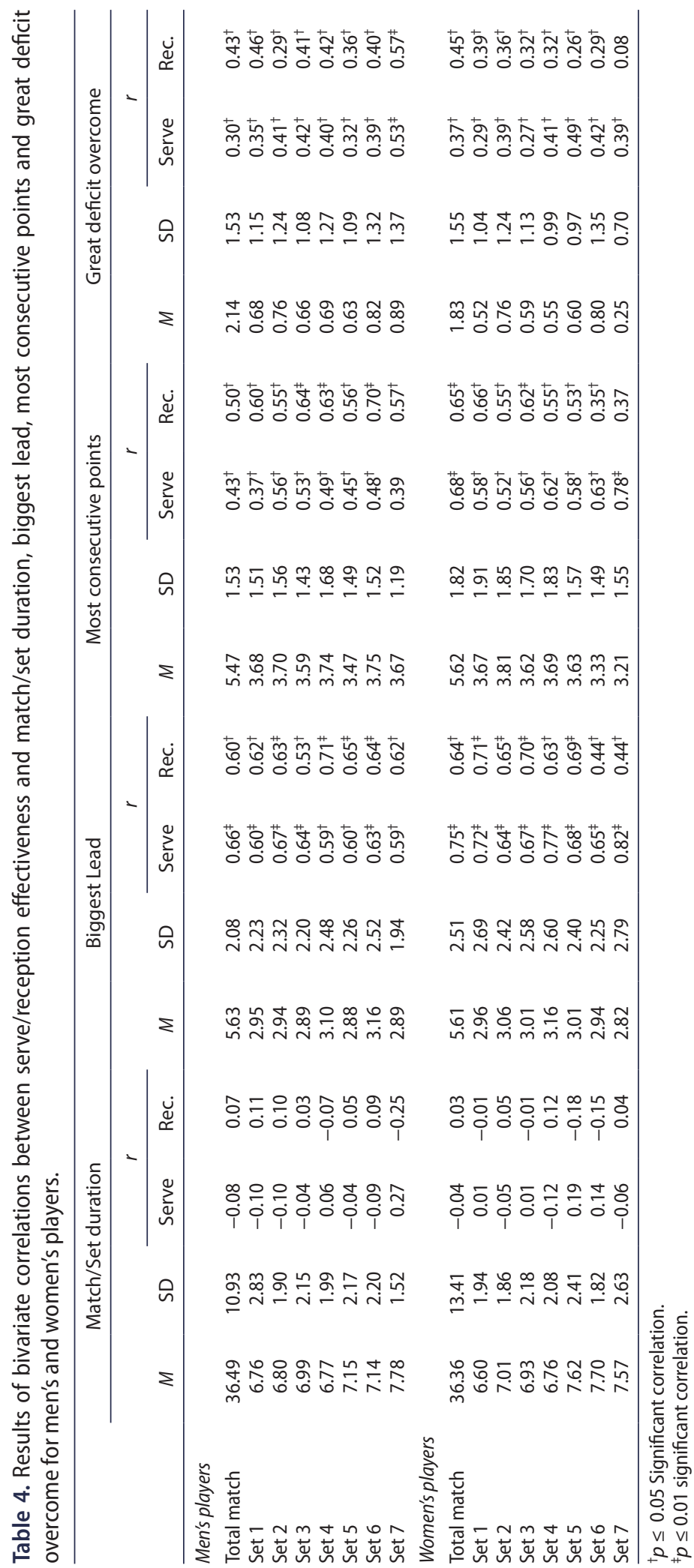




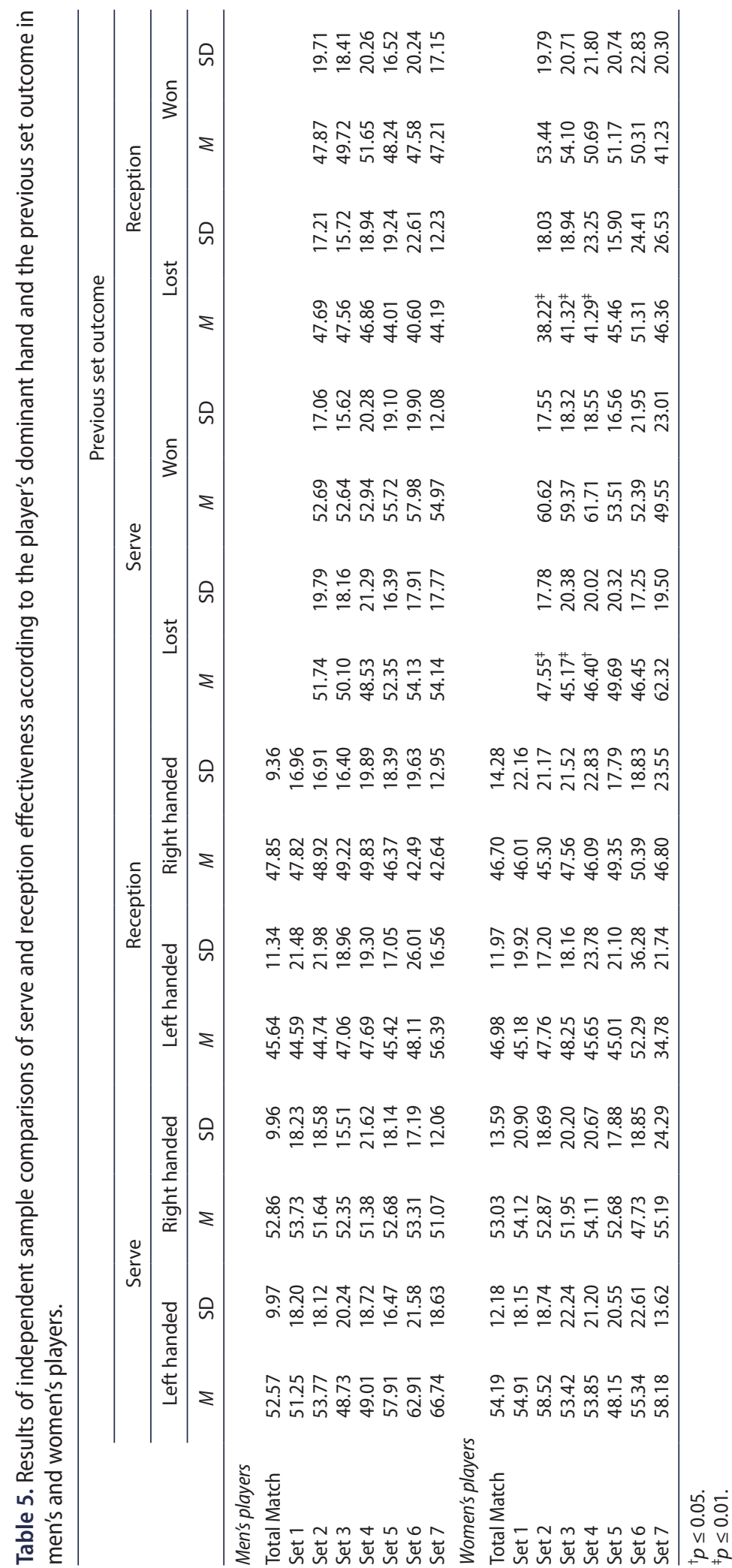


Table 6. Effects of the independent variables on the match serve and reception percentage according to sex (men and women). Beta's 95\% confident intervals are included.

\begin{tabular}{|c|c|c|c|c|c|c|c|c|}
\hline & \multicolumn{4}{|c|}{ Men's players } & \multicolumn{4}{|c|}{ Women's players } \\
\hline & \multirow[b]{2}{*}{ B } & \multicolumn{2}{|c|}{$95 \% \mathrm{Cl}$} & \multirow[b]{2}{*}{$p$} & \multirow[b]{2}{*}{$B$} & \multicolumn{2}{|c|}{$95 \% \mathrm{Cl}$} & \multirow[b]{2}{*}{$p$} \\
\hline & & Lower & Upper & & & Lower & Upper & \\
\hline \multicolumn{9}{|l|}{ Serve } \\
\hline Intercept & $40.74^{\ddagger}$ & 34.17 & 47.30 & 0.00 & $30.98^{\ddagger}$ & 23.74 & 38.22 & 0.00 \\
\hline QO & $-0.02^{\dagger}$ & -0.03 & 0.00 & 0.01 & $-0.02^{\ddagger}$ & -0.03 & -0.01 & 0.00 \\
\hline Hand & 0.21 & -2.65 & 3.07 & 0.88 & 1.36 & -2.09 & 4.81 & 0.44 \\
\hline Match duration & $-0.14^{*}$ & -0.26 & -0.01 & 0.03 & -0.08 & -0.20 & 0.03 & 0.16 \\
\hline Biggest lead & $2.32^{\ddagger}$ & 1.53 & 3.11 & 0.00 & $2.41^{\ddagger}$ & 1.48 & 3.34 & 0.00 \\
\hline Most consecutive points & 0.47 & -0.60 & 1.55 & 0.39 & $1.77^{\dagger}$ & 0.39 & 3.15 & 0.01 \\
\hline Great deficit overcome & 0.61 & -0.33 & 1.55 & 0.20 & 0.41 & -0.73 & 1.54 & 0.48 \\
\hline$R^{2}$ & & 0.44 & & & & 0.60 & & \\
\hline$p$ & & $0.001^{\ddagger}$ & & & & $0.001^{\ddagger}$ & & \\
\hline $\mathrm{F}$ & & 19108.00 & & & & 36175.00 & & \\
\hline Durbin Watson & & 1.71 & & & & 1.65 & & \\
\hline \multicolumn{9}{|l|}{ Reception } \\
\hline Intercept & $27.52^{\ddagger}$ & 20.86 & 34.19 & 0.00 & $22.66^{\ddagger}$ & 14.05 & 31.28 & 0.00 \\
\hline QO & $-0.02^{*}$ & -0.03 & 0.00 & 0.02 & $-0.02^{\ddagger}$ & -0.03 & -0.01 & 0.00 \\
\hline Hand & 1.97 & -0.94 & 4.88 & 0.18 & 1.77 & -2.33 & 5.88 & 0.39 \\
\hline Match duration & 0.00 & -0.13 & 0.12 & 0.96 & -0.02 & -0.15 & 0.12 & 0.81 \\
\hline Biggest lead & $1.99^{\ddagger}$ & 1.19 & 2.79 & 0.00 & $1.59^{\dagger}$ & 0.48 & 2.70 & 0.01 \\
\hline Most consecutive points & 0.80 & -0.29 & 1.89 & 0.15 & $2.30^{\dagger}$ & 0.66 & 3.94 & 0.01 \\
\hline Great deficit overcome & $1.32^{\dagger}$ & 0.37 & 2.28 & 0.01 & 0.81 & -0.54 & 2.17 & 0.24 \\
\hline$R^{2}$ & & 0.46 & & & & 0.48 & & \\
\hline$p$ & & $0.001^{\ddagger}$ & & & & $0.001^{\ddagger}$ & & \\
\hline$F$ & & 19954.00 & & & & 22314.00 & & \\
\hline Durbin Watson & & 1.45 & & & & 2.35 & & \\
\hline
\end{tabular}

skills are essential to succeed, but the psychological and contextual factors are important additional determinants of players' performances (e.g. tactics to choose when serving or receiving). Importantly, the present results showed that serving does not necessarily have to result in an advantage since points won when serving were close to $50 \%$. However, there was a high variability during the sets of the match amongst both genders (i.e. ranging from 50 to 56 in men and from 49 to 56 in women). Performance when receiving was lower than $50 \%$ in both genders with the exception of female players during the 6 th set $(50.81 \%)$. These results reinforce the idea that the first strokes in elite table tennis (serve and reception) are conservative ones where the players try to use the central or close to the net zones to place their first stroke (Malagoli Lanzoni et al., 2014). The fact that values were close to $50 \%$ indicates that serving is intended to get the point started and trying to control the following attacking strokes instead of winning the point directly by very aggressive serves (Bialik, 2016). In particular, Malagoli Lanzoni et al. (2014) argued that the serve plays a key role from a tactical point of view: (a) avoiding the receiver's attack; and (b) allowing the server to attack the returned ball. In fact, $\mathrm{Li}$, Shan, $\mathrm{Li}$, and Sun (2009) identified a recurrent playing tactic of attacking after the serve, but an inconsistent tactic of attacking after the reception. This observation might explain the slight differences in effectiveness when serving compared to receiving. 
The match related results (multiple linear regression) showed the importance of: (a) quality of opposition and biggest lead in both genders when serving and receiving; (b) most consecutive points in women's serves and receptions; and (c) match duration for men's serve. These results are consistent with the available research in racket sports (e.g. tennis) for the quality of opposition variable (O’Donoghue \& Cullinane, 2011), highlighting the importance of strength of opponents when facing a knockout tournament such as Olympic Games. However, this effect was not consistently found during the entire match. This fact can be due to the complex nature of the table tennis game and the increased pressure of knockout tournaments in which a bad day can knock a player out of competition. On the other hand, the biggest lead and most consecutive points variables showed a consistent pattern that most likely reflects the importance of psychological factors (i.e. increased confidence and momentum) in table tennis. In this respect, Kurimay, Pope-Rhodius, and Kondric (2017) found that players use avoidance coping (e.g. behavioural disengagement) and emotional-focused coping (e.g. denial emotions) when they have high levels of cognitive anxiety during the match. It is important to note that the scoring regulation per game (11 points) affects the game dynamics and the impact of leading (i.e. increased self-confidence and less pressure when serving and receiving) complicating an opponent's comeback in the score. Accordingly, the opponent player's performance is more negatively affected during negative psychological momentums than positive psychological momentums (Briki, Doron, Markman, Den Hartigh, \& Gernigon, 2014). The importance of match duration in men's matches probably reflects the role that fatigue (i.e. long matches with more number of shots and less rest time) and concentration have on performance and decision-making when serving (Loh \& Krasilshchikov, 2015).

The variable dominant hand of players did not affect the serve or receiving performances during the total match or the different sets. This fact may reflect that in elite competitions such as the Olympic Games the players are highly skilled and trained to play against both right and left-handed players. In addition, the current research did not control for handedness of both players at the same time (dominant hand of server and receiver). Thus, further research should account for the interaction of handedness when studying the player's effectiveness.

The results of set-by-set performances showed similar serve and reception performance trends for both gender and set. The serve was affected by the biggest lead as a comfortable situation to serve during all the sets. This fact could be related to the influence of bidirectional feelings (positive or negative) during the set according to situational elements that affect the task execution (i.e. better performances when leading) (Sève et al., 2007). In addition, the most consecutive points and the greatest deficit overcome were significant during all the sets. In this respect, Yu et al. (2008) argued that positive feedback (e.g. string of points) has the potential to improve the psychological state and in turn the player's performance when serving. One interesting result is the no significant correlation between serve effectiveness and most consecutive points in men's players during set 7 . This result may reflect the exceptional role of the last set of a match in which the player requires concentration due to the criticality of the context.

On the other hand, the reception results showed that match duration, most consecutive points, greatest deficit overcome, and previous set outcome in female players did not affect set 7. These results are in accordance with Li et al. (2009) showing non-constant performances of reception in elite table tennis. The results may reflect the impact of the last set 
of a match in female players (i.e. higher pressure with fewer risks) and the importance of effectiveness during the first sets of a match. Various lines of research have shown that poor emotion regulation due to pressure can have negative performance consequences in the course of a match (e.g. Martinent, Ledos, Ferrand, Campo, \& Nicolas, 2015). Of relevance in this respect, Ngo, Richards, and Kondric (2017) reported that table players change their serving behaviour as a response to anxiety. These findings may reflect the effects of psychological anxiety and stress during the first and last sets of elite table tennis matches. However, the results showed the opposite pattern in men's players with significant results for most consecutive points and great deficit overcome during all the sets. This finding could be explained by the different responses to pressure conditions by gender (Chalabaev, Sarrazin, Stone, \& Cury, 2008). Female players may be more affected by contextual conditions or the opponents' positive behaviours at the end of a close match (seventh set with reduced differences in the score) where negative feelings and poor self-confidence has a major impact on the match outcome (Chalabaev et al., 2008).

Lastly, the women's performances showed that the serve and reception were highly affected by the previous set outcome during the sets 3, 4 , and 5 (around $15 \%$ of effectiveness differences between win and loss of the previous set). This finding might be explained by the fact that self-confidence after a won set is essential for better performance in the following sets of a match (Yu et al., 2008). In particular, certain similar events, such as positive sensations during a set won (i.e. specific tactics and strokes during positive consecutive rallies) are related to a positive emotional state that favours task execution (serve and reception performance) (Sève et al., 2007).

The present research has some limitations that point to fruitful avenues of future investigation. Future research might want to scrutinise if the present pattern of results would also be found using a point-by-point approach combining quantitative data (effectiveness), qualitative data (player's information), and the contextual-related variables. In addition, performance analysis of each stroke during the rallies should be taken into account in order to identify further influences between serve and reception complexes (i.e. the use of prefixed tactics and shots in each context during a rally). Additionally, some critical events relating serve and reception could be studied such as the effect of timeouts (performances before and after) on players' serve and reception after a break (Martinent et al., 2015). Lastly, we analysed serve and reception separately without taking their interaction into account. Therefore, further research should analyse: (i) the game complexes with strokes 1 and 3 (serving complex) and 2 and 4 (receiving complex) in order to test the influence of opponent-related actions during consecutive strokes (Zhang et al., 2013); and (ii) the analysis of how two players perform (serving and receiving) against each other using point-winning probabilities in order to complement the traditional match statistics and players' rankings (Ley, Dominicy, \& Bruneel, 2017).

In conclusion, the present article highlights the importance of contextual-related variables on serve and reception behaviour in elite men and women's table tennis. The main findings show a heterogeneous result pattern that was substantially affected by gender and the current set being analysed. The emerging results from the regression analyses reflect the influence of technical, tactical, and psychological factors on elite table tennis performance during knockout championships (Yu et al., 2008). From a coaches' point of view, and in a very broad sense, the results indicate the necessity of implementing psychological skills training to ensure performance stability in elite table tennis matches: e.g. self-confidence 
management techniques such as positive self-talk, slow-paced breathing or visualization in order to support and assist the players during phases of increased pressure and anxiety (i.e. such as the 6th and 7th set or after an opponent's comeback in the score) (Kurimay et al., 2017). Moreover, technical-tactical training interventions should take the above mentioned suggestions into account when preparing for competition. Specifically, the use of tasks that simulate real scenarios of a match should be implemented based on the current findings (e.g. playing actions serving during the $3 \mathrm{rd}$ set after losing the previous set and with a difference in the score of 3 points).

\section{Disclosure statement}

No potential conflict of interest was reported by the authors.

\section{ORCID}

Miguel-Ángel Gómez (D) http://orcid.org/0000-0002-9585-3158

Antonio García-de-Alcaráz iD http://orcid.org/0000-0001-8210-4118

\section{References}

Bialik, C. (2016, August 18). Serving is a disadvantage in some Olympic sports. FiveThirtyEight. Retrieved from https://fivethirtyeight.com/features/serving-is-a-disadvantage-in-some-olympicsports/

Briki, W., Doron, J., Markman, K. D., Den Hartigh, R. J., \& Gernigon, C. (2014). Differential reactions of virtual actors and observers to the triggering and interruption of psychological momentum. Motivation and Emotion, 38(2), 263-269.

Chalabaev, A., Sarrazin, P., Stone, J., \& Cury, F. (2008). Do achievement goals mediate stereotype threat? An investigation on females' soccer performance. Journal of Sport and Exercise Psychology, $30,143-158$.

Glazier, P. (2010). Game, set and match? Substantive issues and future directions in performance analysis. Sports Medicine, 40(8), 625-634.

Kurimay, D., Pope-Rhodius, A., \& Kondric, M. (2017). The relationship between stress and coping in table tennis. Journal of Human Kinetics, 55(1), 75-81.

Lees, A. (2002). Technique analysis in sports: A critical review. Journal of Sports Sciences, 20, 813-828.

Leite, J. V. M., Barbieri, F. A., Miyagi, W., Malta, E. S., \& Zagatto, A. M. (2017). Influence of game evolution and the phase of competition on temporal game structure in high-level table tennis tournaments. Journal of Human Kinetics, 55(1), 55-63.

Ley, C., Dominicy, Y., \& Bruneel, W. (2017). Mutual point-winning probabilities (MPW): A new performance measure for table tennis. Journal of Sports Sciences. doi:10.1080/02640414.1400261

Li, Z. B., Shan, Y., Li, H. S., \& Sun, L. (2009). A re-study on the evaluation criteria of table tennis technique. Journal of Beijing Sport University, 10, 26-28.

Loh, T. C., \& Krasilshchikov, O. (2015). Competition performance variables differences in elite and U-21 international men singles table tennis players. Journal of Physical Education and Sport, 15(4), 829.

Malagoli Lanzoni, I., Di Michele, R., \& Merni, F. (2014). A notational analysis of shot characteristics in top-level table tennis players. European Journal of Sport Science, 14(4), 309-317.

Marcelino, R., Sampaio, J., \& Mesquita, I. (2012). Attack and serve performances according to the match period and quality of opposition in elite volleyball matches. Journal of Strength and Conditioning Research, 26(12), 3385-3391. 
Martinent, G., Ledos, S., Ferrand, C., Campo, M., \& Nicolas, M. (2015). Athletes' regulation of emotions experienced during competition: A naturalistic video-assisted study. Sport, Exercise, and Performance Psychology, 4(3), 188-205.

McAfee, R. (2009). Table tennis steps to success. Champaign, IL: Human Kinetics.

McGarry, T., Anderson, D. I., Wallace, S. A., Hughes, M. K., \& Franks, I. M. (2002). Sport competition as a dynamical self-organizing system. Journal of Sports Sciences, 20(10), 771-781.

McGarry, T., \& Franks, I. M. (1996). In search of invariant athletic behaviour in sport: An example from championship squash match-play. Journal of Sports Sciences, 14(5), 445-456.

Ming, C. L., Keong, C. C., \& Ghosh, A. K. (2008). Time motion and notational analysis of 21 point and 15 point badminton match play. International Journal of Sports Science and Engineering, 2(4), $216-222$.

Ngo, V., Richards, H., \& Kondric, M. (2017). A multidisciplinary investigation of the effects of competitive state anxiety on serve kinematics in table tennis. Journal of Human Kinetics, 55(1), 83-95.

Ntoumanis, N. (2001). A step-by-step guide to SPSS for sport and exercise studies. London: Routledge. O’Donoghue, P. (2010). Research methods for sports performance analysis. Oxon: Routledge.

O'Donoghue, P., \& Cullinane, A. (2011). A regression-based approach to interpreting sports performance. International Journal of Performance Analysis in Sport, 11(2), 295-307.

Palut, Y., \& Zanone, P. (2005). A dynamical analysis of tennis: Concepts and data. Journal of Sports Sciences, 23(10), 1021-1032.

Pfeiffer, M., Zhang, H., \& Hohmann, A. (2010). A Markov chain model of elite table tennis competition. International Journal of Sports Science \& Coaching, 5(2), 205-222.

Ramsey, J. (1969). Tests for specification errors in classical least squares regression analysis. Journal of the Royal Statistical Society, 31, 350-371.

Sève, C., Ria, L., Poizat, G., Saury, J., \& Durand, M. (2007). Performance-induced emotions experienced during high-stakes table tennis matches. Psychology of Sport and Exercise, 8(1), 25-46.

Tamaki, S., Yoshida, K., \& Yamada, K. (2017). A shot number based approach to performance analysis in table tennis. Journal of Human Kinetics, 55(1), 7-18.

Vilar, L., Araújo, D., Davids, K., \& Button, C. (2012). The role of ecological dynamics in analysing performance in team sports. Sports Medicine, 42(1), 1-10.

Yu, L. J., Zhang, H., \& Hu, J. (2008). Computer diagnostics for the analysis of table tennis matches. International Journal of Sports Science and Engineering, 2(3), 144-153.

Zhang, H., Liu, W., Hu, J. J., \& Liu, R. Z. (2013). Evaluation of elite table tennis players' technique effectiveness. Journal of Sports Sciences, 31(14), 1526-1534. 